Dr Chris Hughes

Edge Hill University

St Helens Road,

Ormskirk,

Lancashire,

United Kingdom,

L39 4PQ

01695584756

chris.hughes@edgehill.ac.uk

ORCHiD - 0000-0002-0259-4979 


\title{
A Song of the Paddle: Haptic Aesthetics of Canoe Travel in the English Lake District
}

\begin{abstract}
This paper is a critical exercise in haptic aesthetics. Drawing upon Fisher (1997) and Patterson's (2007) ideas, the paper applies some of the core sentiments from what has been called 'haptic aesthetics'. The subject matter of such an inquiry is a rather simple one, namely, me in a canoe with a paddle and nowhere in particular to go, in essence, a form of leisure travel explained phenomenologically. Such humble beginnings are interspersed with arguments that illustrate haptic aesthetics along epistemological lines. Further still, it will be shown that paddling as a sensuous leisure activity is deeply haptic but also acoustic and the theory of 'soundscape ecology' will be used here to help further describe the sound and feeling of paddling a canoe in a natural environment. It is in this theoretical and sensory connection that readers should notice some ethical connotations and it is also such a connection that illustrates what could be called a 'practical' or 'everyday' aesthetics of leisure.
\end{abstract}

\section{Keywords}

Haptic aesthetics, phenomenology, senses, technology, paddling.

'One makes oneself someone by giving oneself form' P. 2

'One walks down the path to get somewhere, but one enjoys walking, and one can leave one's house just to walk' P.21

Alphonso Lingis - Sensation: Intelligibility in Sensibility

\section{Prelude}

As a family we like spending time on water in our canoe. My wife and I have the unenviable task of lifting and strapping 4.80 meters of green fiberglass onto our campervan before two 
young boys can splash and relax peacefully around the English Lake District. When on the water, the boys may sleep, blow the whistles on their buoyancy vests or dip an occasional paddle when it suits. We don't just go 'somewhere'; instead we just enjoy paddling 'the going'.

Shifting the boat complete with all these passengers can take some reasonable physical effort however paddling it solo is a completely different leisure, and as will be described, haptic, experience altogether. The lean of the boat, the rhythm, the subtle adjustments to steer and the physical exertion prove very delicate, very sensuously different and very endearing. The logistics of launching and portaging are also very different. Whereas we all help with this when out together, preparing to paddle sole demands the carrying of a 40kg boat using a traditional method that includes the rolling, tilting, lifting and then resting and balancing of canoe over ones head and on ones shoulders (a brilliant visual demonstration is provided in Waskul and Waskul, 2009). These skills have taken some time to learn and involved many a grimace indeed. A whole different repertoire of movement (or 'knack') has also been developed through the senses whereby a completely different paddling style with some different strokes, techniques and rhythm can be adopted and experienced. This will form the central activity of this paper in due course.

In attempting to economically paddle solo, I recently purchased a beautiful handmade wooden paddle. This 'Voyageur' styled paddle is a $162 \mathrm{~cm}$ combination of cherry and walnut that has been expertly crafted with a super thin yet remarkably large blade that thus allows the movement of lots of water with minimal effort (the blade alone measures $81 \mathrm{~cm}$ ). 


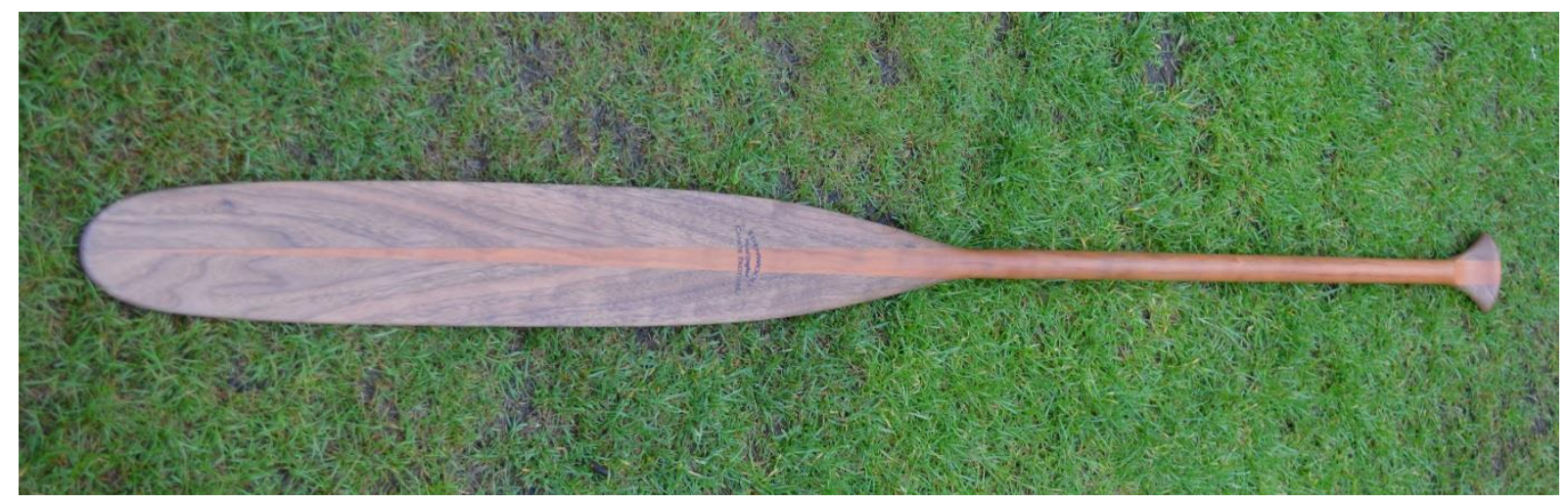

Paddles like these have been designed and indeed cultured by communities of

'Voyageurs' over centuries to facilitate travel over huge distances on water, much

different to the leisure pursuits here focused upon. The precision carved lightweight

blade allows the rhythmic sweep through the water and also what is often referred to amongst paddlers as the 'Indian stroke'. The sensuousness and knack of this stroke will be described later in the paper to show how paddling can evoke experiences and as will be argued, aesthetics, that are deeply haptic.

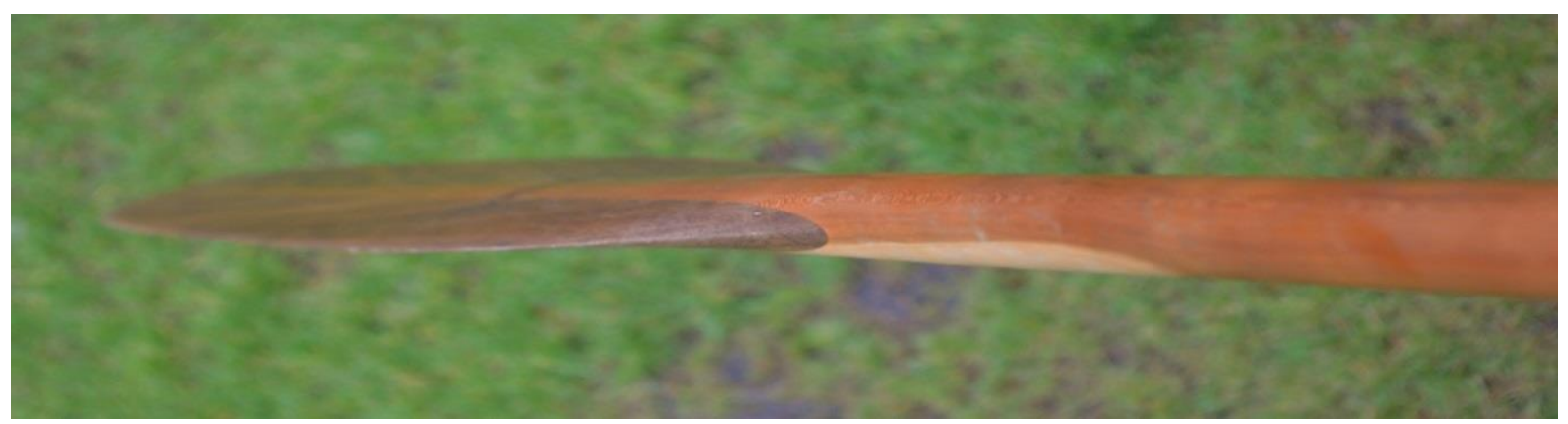

This paper has been approached in an organic, original and honest fashion. The simple aim has been to paddle the boat, jot notes and then let one's mind wander before some refinement. This has become, as will be discussed later, an exercise in phenomenology. In drawing upon the burgeoning discussions of the senses and embodiment in sport, physical culture and leisure, the paper will introduce the idea of haptic aesthetics to an analysis of leisure 
experience. The paper offers an argument about the economic and 'aesthetic' value of leisure and its associated equipment to raise some novel questions concerning our consumption and construction of aesthetics with such equipment. Haptic aesthetics will illustrate that experience with equipment is a multi-sensory endeavor and it will be shown through this phenomenology that experiences are 'lived' (corporeally and cognitively) as opposed to being solely 'known' at the cognitive level (Merleau-Ponty, 1962, Allen-Collinson, 2009). Whilst the paper works to discuss aesthetics, the actual phenomenology is itself an experiment in aesthetics to see how experiences can be worked with linguistically. This is offered to readers in the latter sections to seek their aesthetic judgment.

Some stylistic influences within the paper (either explicitly cited or implicitly applied) include the stirring travel writings of Henry David Thoreau, the lucid and rhythmic phenomenology of Alphonso Lingis and also the films and writing from the adventurer and canoeist Bill Mason. More centrally, the paper owes much to the maker of my paddle, the outstanding craftsman Tim Rowe whose expertise, care and delicacy inspired much of this paper (in focus and also style) and in part shapes the aesthetic. These musings on the water stem from watching him meticulously carve and refine this very paddle. Unbeknown to him at the time, his craft has stirred up many philosophical ideas and this paper is a short exercise in one of them. Principally it is about simplicity, the simplicity of leisurely moving in water.

\section{Sensuous sport and leisure}

Some scholars of the senses in working under a broadly anthropological or sociological remit have offered interesting analyses of the sensuousness and aesthetics of physical culture, leisure activities and their associated skills. Maier (2016) shows us how skateboarders as aural architects (Blesser and Salter, 2007) work within, travel through and actively contribute 
to, the soundscape of cities. Another form of physical travel and mobility, distance running, has been discussed in terms of the sensuousness and phenomenology that it evokes (Hockey, 2006). The evaluation of running routes for Hockey (2006) is as much a sensuously haptic matter as it is visual; via the feet in running shoes, 'it is a directly embodied way of feeling the world and understanding its properties' (197). Following these authors, this paper also focuses on a physical means of leisure travel however it is hoped that a consideration of the technologies of such travel will elicit some interesting and under examined questions where the aesthetics of leisure, travel and environment are concerned.

As a catalyst for debate around the senses and physical activity and sport, Sparkes (2009) provoked some interesting thoughts when cricket bats and football boots are offered as examples of useful sensory and pedagogical markers of importance for researchers of physical culture. More recently, paralleling the critical debates within the social sciences and humanities, those working within physical culture have approached the sensuousness of physical activity and leisure with a wealth of methodological diversity. This is evidenced in the most recent edited collection of papers (Sparkes, 2017) in this area. More specifically, the intimacy of human touch is illustrated by Palmer (2016) whose relationship with climbing boots is offered much like the work of Ingold (2004), as a reminder or indeed inspiration to consider how our feet have a very precarious yet also comforting contact with footwear and terrain. Allen-Collinson and Hockey (2011) also remark upon the sensory importance and delicacy of selecting footwear for distance running. In their fascinating paper that takes a phenomenological outlook towards middle distance running, scuba diving and the embodiment debate, the authors call for and start to show us an understanding of the nuance of (a) the embodied, (b) the inter-embodied and (c) the embodied via auxiliaries. My learning to paddle a canoe appears to traverse such a three-way typology and this paper operates as an 
offering of critical remarks on the haptics and acoustics of this form of leisure. Readers will appreciate a blurring of self, environment and technology to vividly portray an embodied phenomenological watercraft.

Continuing with the aquatic theme, Merchant (2011) dives under the surface to explore the 'unrepresentable' somatic senses that were actively constitutive in developing a submarine sensorium during scuba diving courses. Beyond the immediacy of wetsuits, buoyancy and water pressure, her paper then goes on to explore how videography is re-sensed during participants' post-dive viewing of the sub aquatic film. It here again becomes clear that our senses are not only directly influenced by our surroundings, be them cultural, social, environmental or architectural, but also by the technological things we use, wear or learn through during our physical and leisure based activities. The senses are in other words central to leisure and our being leisurely; sentiments echoed by Humberstone (2011). The focus of Humberstone's (2011) ethnographic work is windsurfing and here the elemental nature and sensory connection between body and environment is explained with pedagogical emphasis. With similar undertones, Brown's (2017) auto-ethnography illustrates a sailing identity as one that is skilled, shaped and attuned out on the open water.

In Butler (2016) we see a fascinating and lucid description of what is essentially AllenCollinson and Hockey's (2011) typology but this time on horseback. In evocative detail, Butler (2016) provides a window into the 'feeling of the game' of a jockey complete with a sensuous 'intertwining of human and horse within the workplace' (4). In drawing phenomenological and sociological inspiration from Maurice Merleau-Ponty and also Pierre Bourdieu, Butler (2016) evocatively illustrates the 'work' that is conducted in the saddle, on the horse out on the gallop. 'Clothing, the playing surface, the location and spectators all 
become part of the feel for the game' so Butler $(2016,12)$ states by showing us how such 'feelings of' are developed through learning and also occasionally lost before being regained in what appears to be an enmeshing sensuous epistemology. Jackman, Fitzpatrick, Lane and Swann (2017) also drawing upon data from equestrian describe the lightness of touch, optimal arousal, balance and kinesthetic feel experienced by jockeys in a state of 'flow'.

The feeling referred to in Caudwell (2015) is a 'blue' one. Here a personal narrative autoethnography focuses on the underrepresented voice of females who suffer mental health issues and such feelings of 'blue'. The rhythmic motion, mundane, repetitive and occasionally slow movements on a rowing machine are described to show how these are embodied pleasures for her. The slowness and meditative silence of paddling will be described shortly and readers should be able to appreciate and resonate with the pleasures evoked through this leisure travel.

Adopting phenomenological approaches and sociological analyses, Allen-Collinson and Leledaki (2015) explore how the sensuous and intense embodiment of the outdoors, or more precisely, the 'being-in-the-out-door-world', encompasses corporal awareness of pleasurable 'elemental highs'. Building upon this work and in seeking to describe my own water leisure, this paper will contribute to this growing body of work that questions the 'neglect of the particular, existential, material dimension and under-theorisation of the lived, and often intensely corporeal aspects of our leisure activities' (Allen-Collinson and Leledaki, 2015, 467). The haptic sense that features prominently within Allen-Collinson and Leledaki (2015) will be problematised in the following section to show a literal and figurative illustration of how leisure can be grasped. Further still, haptic aesthetics will be shown to further develop 
the well-established embodiment debates to follow Crouch (2010) yet offer a new and more philosophically rich 'route into a more human-orientated comprehension of leisure' (63).

\section{Haptic aesthetics}

Paterson's (2007) conceptualisation of haptic aesthetics will be applied to illustrate the aesthetic connotations of much of the excellent research previously mentioned, but also to add another important philosophical thread into what currently appears to be a broadly phenomenological approach to the senses in leisure. Paterson (2007) shows us that despite aesthetics usually being associated as the branch of philosophy that deals with art, the word itself is rather more delicate and nuanced. It is beyond the scope of this paper to rehearse all the etymological and historical discussions concerning aesthetics however a few thoughts will be useful to firstly help get a handle on the word but also secondly, to appreciate and perhaps adjust its applicability when we think about the everydayness of leisure where this could be applied.

Paterson (2007) arrives at an Aristotelian understanding of aesthetics. In short, Paterson (2007) illustrates how the word 'aesthetics' has throughout the history of philosophy often been appropriated with ideas of 'sensory faculty', 'sensory perception', 'art and beauty' and also 'judgment' to follow Kant. In ways that illustrate the epistemological connotations of the senses and sensations, the word 'aesthetics' for Serematakis (1994) stems from the Greek word 'aesthenome' thus denoting what she understands as 'I feel or sense, I understand, grasp, learn' (5). Understood as such, the aesthetic quickly comes into shaper focus and becomes more applicable when we reconsider much of the research that was introduced earlier. Aesthetics in this way could be understood similar to the learnt 'feelings of' as described by Caudwell (2015) and also Butler (2016). Considered as part of an 
epistemological process, such 'feelings of' one may suggest are not mere arbitrary subjective happenings but instead deeply effective and affective qualities within the learning of many replicable skills and activities that permeate leisure.

Space does not permit a regurgitation of a whole history of such a contested branch of philosophy but there are some important points here to help readers appreciate the aesthetic in more contemporary times. Fisher's (1997) project of 'aesthetic redefinition' was an ambitious attempt to rethink the term aesthetic along pre-modern sensory lines. Rising from dissatisfaction with the reduction and marginalisation of the word to notions of style, attitude, judgement or theory of art, she notes how the word 'aesthetic' can be understood in two distinct ways.

In its more dynamic sense the aesthetic can be understood, first, as the relational form, one which can account for the aesthetic attendant in processes of identification, social affiliation and discursive practice; and second, as involving sensory mediation of social states and cultural formations. (Fisher, 1997, 1)

Fisher's ideas encourage a movement beyond the simple association of the aesthetic with art, and a singular understanding of art as being solely visual. This approach to aesthetics is one that is more sensuously complex and appreciates the haptic sense as being a broader 'orientation to sensuality' (Young, 1990, 182). Such an orientation, as will be argued, is evidently central if at times under represented in analyses of leisure. Whilst such thoughts appear provocative, novel and interesting, Fisher (1997) still places the notion of the aesthetic in the shadows of its familiar correlative, art. This is inevitable and potentially unavoidable when we consider its frequent linguistic usage. It does however appear that this is rather limiting and whilst I would sensibly concede that we cannot have art without aesthetics, it does not follow that we only get aesthetics through art. The thorny issue at play here has also 
divided philosophers; nature proves rather problematic for the concept of the aesthetic. This paper takes as its backdrop the nature and geography of the English Lake District, this isn't art but it certainly can be deemed beautiful and therefore of aesthetic value. A painting of the Lake District can be art but the Lake District cannot for obvious reasons. Despite Fisher (1997) showing us how a 'more immanent and relational' aesthetics can help us think about not only objects but experiences, her 'haptic aesthetics' nonetheless focuses on the experiences of, from and with art objects (of various forms). My attempt in this paper is to promote some ideas about the applicability of haptic aesthetics to our everyday non-art experiences of leisure and the equipment and technologies used for such. It is from here that ideas about art will make way for important ideas about the everyday practical aesthetics of leisure, nature, travel and technology.

In his excellent treatment of the senses of touch, Paterson (2007) takes a slightly more philosophical approach to 'haptic aesthetics'. In borrowing a quote from Merleau-Ponty (1969), he posits haptic aesthetics as being concerned with 'how the world touches us' (245). Like Fisher (1997), Paterson (2007) takes several examples from art as sources of inspiration for his theoretical ideas but if we approach Merleau-Ponty's remark logically, it becomes clear that 'the world' to which he refers cannot, and need not, be art or artistic in order to touch us. It appears perfectly plausible that Merleau-Ponty's aesthetics can be applicable to non-art objects and further still, the experienced aesthetic and haptic touching of, and from, non-art objects and the world as is experienced during leisure.

Putting aside the many difficulties with the notions of aesthetics and the haptic, what proves particularly useful to scholars of the senses is that the haptic should be understood as being both proximal and distal and therefore not necessarily in opposition to the optical (as has 
historically been the case with understanding the 'five senses' as individual systems of perception), but instead in some form of collaboration. Equally, following Deleuze and Guattari (1988) and also Paterson (2007) we can understand haptic space as not solely touch oriented but potentially visual and also auditory. Our leisure activities are unquestionably multi-sensory and it could be argued therefore that rich and vivid analyses of leisure should critically consider the role of the senses and sensation to fruitfully describe and understand the very things that make us want to participate in leisure and the ways in which leisure environments are grasped and at the same time grasping. To some degree the papers previously cited demonstrate this in either implicit or explicit terms and they operate in keeping with the now widely accepted turn towards the entangled senses in the social sciences and humanities. It is now where some thoughts about audition and soundscape ecology can help us appreciate the aesthetics of everyday leisure and further the idea of the haptic as being in part auditory. In addition, the notion of soundscapes will also elucidate Merleau-Ponty's (1969) ideas of how the world (via our touching of it) touches us.

\section{Soundscapes}

In a recent paper, Carla Maier (2016), offers an acoustic insight and transcultural anthropology of the sound of skateboarding. Great inspiration has been drawn from Maier here to offer several additional ideas to help us work with sound and think about the combination of sound and environment during leisure activity. In briefly considering the theory of soundscape ecology readers will appreciate the different layers and contributors of sound within environments, and recognise the enmeshing of sound and how a microepistemology of sound (LaBelle, 2010) is operated in a canoe on water. 
Soundscape ecology involves the detailed recording and representation (via spectrograms) of the sonic signatures of environments and landscapes. Its inception is usually attributed to an edited collection of work by Truax (1978). As a way of example, scientists conducting this form of inquiry record the acoustic changes within environments in an attempt to ascertain the implications of sonic ecology. To illustrate this practically, my house is located on the very edge of one of the busiest stretches of the M6 motorway in the north of England. The north bound inside lane is literately just beyond the fence at the foot of my garden. A soundscape ecologist may be interested to understand how this environment sounds differently over a period time. Their analyses would seek to understand the different layers of sound within the environment. These layers generally include and apply to the 'biophony' or sound created by organisms (bird song for example), the 'geophony' as being non-organism (elemental) sound and thirdly, the human created 'anthrophony'. How has the dawn chorus sonically evolved in this location over a period of time when the motorway becomes busier and noisier? I leave such a question to the experts with precision recording devices but the principle of the question and the categorisation of sound appear useful and thought provoking for many scholars of the senses regardless of their disciplinary and paradigmatic persuasions.

This layering or categorisation of sound will feature later to delicately help describe my sound on the water and to raise some ideas about the haptic aesthetics and ethics of my watercraft. Waterways are an understandable yet somewhat disappointing omission from La Belle's (2010) excellent treatment of acoustic territories. Blesser and Salter (2009) are likewise concerned with the aural architecture of dry land much like Maier (2016) whose analysis of skateboarding elicits how sound is composed within the city by skateboarders and a variety of other pedestrians. Their active contribution to or contestation with the cacophony of the city is of social and cultural interest in many ways however my own focus within this paper is on the 
equipment used by us during our aural and haptic architecture generally and as aquatic architects in particular.

Away from dry land, Lake Windermere features in Collins' (2011) case study research concerning the noise on water and the politics of noise in such environments. Collins (2011) discusses the historical tensions surrounding the soundscapes that are National Parks and illustrates how legislation and policies have in effect marginalized loud leisure activities (powerboating and waterskiing) and thus radically altered the geophany and anthrophony (Traux, 1978) of the waterway and the associated cultural formations (Fisher, 1997). A more detailed sonic description will feature shortly but the focus of discussion now turns towards the technologies of our leisure and their associated haptic aesthetics.

\section{Haptic Technologies}

What becomes clear is that a consideration of aesthetics along sensuous lines allows us to understand the aesthetic as not solely a property or value within things like objects, artifacts or landscapes but instead as an experience. Continuing with the Merleau-Pontian influence, such experiences are with, not just of things. By way of example, whilst my paddle has aesthetic qualities, and whilst it was in no doubt crafted in part with some sort of aesthetic premise and property in mind (its curve, lines and smoothness), its experiential aesthetic only becomes significant with me. It can be understood aesthetically as an appendage designed and used for the purpose of travel but this should be of no less importance than questions concerning the aesthetics of art. Whilst the paddle, unlike art objects, can exist and succeed without an appreciation of the aesthetic in the traditional sense at least, our earlier revision of the aesthetic now places this concept in very close relation to any technology or equipment that by its design, and use, makes us sense things. 
Manufacturers of golf clubs, cricket bats, running clothing and fishing rods never seek to create ugly and uncomfortable products. Cosmetic products, cars, kitchen equipment and the well-known brand of fruit named computer on which I type are all carefully created, branded and marketed with certain aesthetics, and further still, haptic aesthetics in mind. Most readers would sensibly concede that some thing or product visually 'looking good' is one obvious aesthetic consideration, but how it 'feels' (via our haptic senses), 'performs' and 'connects' with us is a very different, very intimate and significant issue for the consumer. Many of the truly successful products and technologies that are used within our everyday lives may look good and be quantitatively consistent and credible however it is the qualitative 'feel' of shaving razors, computers, musical instruments and tennis rackets that make us use, trust, adore and then frequently repurchase them. A rock-climbing friend reminded me that people don't scale difficult and dangerous multi-pitch routes with equipment that doesn't 'feel' right. In a similar vein, another friend confessed to still owning and using his original Apple IMac (released in 1998) simply because it 'always feels good'. No doubt many readers of this journal will have similar yet idiosyncratic affinities to equipment and technologies for their leisure.

Hockey and Allen-Collinson (2007) and Allen-Collinson (2009) have put forth a phenomenological argument concerning how sportspeople are 'inextricably intertwined' (283) with equipment, kit, environment and terrain. In drawing upon the phenomenology of Merleau-Ponty (1969), this blurring of self with other, this enmeshing or intercorporeality, operates with equipment of various kinds thus resulting in a bio-technological conceptualisation of the body. As is equally evident in the evocative phenomenological prose of Lingis (1996), bicycles are fitted with bodies by way of their and our form. This bodily and technological synthesis inverts drastically subject/object dualism and as will be illustrated 
later in this paper, this blurring of self with or on technology and equipment operates as haptic aesthetics.

The intention here is to illustrate how our usage of many forms or technology and leisure equipment is qualitatively and haptically apprehended and that this use $i s$ the very meaning of aesthetics. There is a huge range of technologies and equipment used in leisure activities let alone our general everyday lives and it is hoped that some critical remarks and provocations about this taken for granted equipment will instigate some broader thoughts for readers concerning its use to shape haptic aesthetics of leisure.

Considering leisure consumption on a macro scale, with social and cultural value aside, there are considerable difficulties and limitations associated with trying to establish a credible economic value of physical activity/leisure equipment and apparel. In England alone, the National Governing Body for Sport, Sport England (which in this case should be understood as speaking very generally for and about competitive sport, recreational sport, leisure and physical activity) estimated the annual economic worth of equipment and sportswear as being $£ 3.18$ billion of the gross value added to the English economy (Sport England, 2013). It is left to readers to ponder the global worth of such equipment, clothing and technologies but one hopes this at least sheds some light on what now appears to be an interesting issue concerning how our economic and sensuous consumption of such items operates aesthetically. Thinking about international consumption and multi-national corporations, Apple (2017) project revenue figures of between $\$ 76-78$ billion for the first quarter of 2017 . The Nike brand claim $\$ 8.5$ billion of revenue for the same quarter (Nike, 2017) thus leaving us to make a logical interpretation - our purchase and engagement with their products for our leisure is clearly economically powerful and such an engagement is in a significant way deeply haptic. 
Understood as such, haptic aesthetics is clearly very big business and the sensuousness of our leisure is in part heavily shaped by big businesses. This dynamic inevitably warrants further critical consideration.

Put rather crudely, the designers and manufacturers of such items as the ones mentioned previously place enormous importance in the intended 'look' and 'feel' of and for their products. As consumers with such products we unlock the aesthetic value. Manufacturers also appreciate that how these 'feel' to, and between us, can be qualitatively different yet their

industries rely significantly on us 'feeling' collectively good, comfortable and satisfied with our purchases nonetheless. People do not invest money and time in buying and then continuing to play golf with an ugly putter that 'feels' awkward to use. We are insatiable consumers of things that 'feel' good, right, beautiful, sleek etc. Stretching this argument further, Paterson (2007) insightfully highlighted the possibilities of technological engineering and its engagement of the haptic senses. Indeed, hundreds of millions of smartphone users the world over are now in touch by touch and are becoming increasingly more touched by their devices in a variety of ways. Such 'connection' as the manufacturers call it is heavily predicated on their device being touchable and such touch being so intimate that we as consumers remain loyal (in touch) to the brand as a 'functional unit' (Lingis, 1996) with it.

\section{A methodology in movement}

This paper adopts a phenomenological approach to the research inquiry. The case has been made in great detail for the potential philosophical contribution (Kerry and Armour, 2000; Allen-Collinson, 2009), sociological connotation (Hockey and Allen-Collinson, 2007) and methodological and haptic application (Allen-Collinson and Leledaki, 2015) of phenomenology within leisure, sports studies and physical activity. Taking the leisure pursuit 
of paddling as the focus, phenomenology is particularly useful to help describe and work with the experiential and situated 'being-of-the-world' to follow Merleau-Ponty (1962). Leisure is not an 'out there' object to be experienced; working with a Merleau-Pontian (1969) outlook, leisure is about 'intercorporeality', we touch and are touched by leisure. In drawing attention to our entwining (Hockey and Allen-Colinson, 2007; Allen-Collinson, 2009) with equipment and technology, phenomenology appears to be a useful means to help work with describing the make up of such a fabric and how we are connected with equipment in the form of 'functional units' (Lingis, 1996). As such, and to follow Allen-Collinson (2009, 291), the writing of phenomenology should strive for a textured and 'sensuously detailed' representation that is proportionately descriptive and analytical. In this particular case, the aim is to facilitate the reader's interpretation into, and through, the canoe being paddled.

Phenomenology is not a unified and clearly demarcated philosophy or for that matter, branch of philosophy. Instead, it operates more in keeping with a method of doing philosophy, in particular (via Merleau-Ponty), a method and approach to doing existential philosophy. This school of philosophy, (usually associated with Kierkegaard, Nietzsche, Husserl, Heidegger, Kafka, Sartre, deBeauvoir and Camus) has traditionally sought to work with the idea of 'being' human and the associated morality, angst and variety of desires of humanness. The value of phenomenology lies in its being facilitative in describing the paradoxical presence and absence (Leder, 1990), taken for granted aliveness and sensuousness of being human. Herein lies its applicability for this paper; the phenomenological method enables one to work with one's very being of human and ones being such with other things in a haptic intertwining. Its very strengths and quests may indeed be deemed its flaws for some, if or where, a more analytical or relational approach to empirical and conceptual matters may be preferred. Along these lines, phenomenology is not qualitative research. 
For the purposes of this paper, the phenomenology of Alphonso Lingis proves extremely useful. As a respected translator of Merleau-Ponty, Lingis is perfectly equipped to navigate some of the sensuously entangled and ambiguous topics of being mortal, susceptible, active, responsible and communicative (Lingis, 1996). His lucid phenomenology operates not as language through experience but instead as an experience with language. This is an important distinction and one that helps further the case for the merits and contribution offered by phenomenology. It works 'not to record and retain a passing insight, but to intensify a present and future power' (Lingis, 1996, 95). This is phenomenology's analytical thrust. The power being spoken of here is one of emancipation, freedom and the joys of sense and the intelligibility of sensation. In following and applying these ideas of Lingis (1996), the remainder of this paper seeks to shed light on the normality of being present and to analytically show leisure as an alive, intercorporeal and aesthetic endeavor.

\section{The sensuousness of travel - A Song of the Paddle.}

The abrasive scraping of plastic on stone makes way for a gentle lapping sound of water against the canoe as it delicately bobs upon the shallow water of Lake Windermere. The first passage is made from land to water; the transubstantiation is induced. The once dry canoe is now wet and of the water. Already on board are a small dry bag containing a few essentials (money, van keys, bottle of water and three cold pork pies), a buoyancy vest (despite no intention of wearing it) and my long thin paddle. Wading out two metres provides a harsh reminder of the summertime water temperature of England's largest body of inland water. A brief shiver is a small price to pay for still conditions and the promise of a fine days paddling. With one wet leg carefully placed in the centre of the canoe, a quick hop brings the other one 
aboard with a gentle nudge away from the pebbly shore. A brief roll of the boat and swift leg shuffle allow a comfortable crouch on the kneeling thwart of the vessel.

These skills of launching and kneeling have become part of my bodily repertoire, they've taken a little conscious practice but they are in large stipulated by the very craft and pursuit. Much like a bike, one fits onto it and one does what the bike demands. Unlike my past fallings from bikes, I'm yet to fail hopelessly with the canoe and flop inelegantly into the water. From here on the paddle is needed and with two brisk swipes of its blade the direction is corrected and we are set on a nice course out of the bay. A gentle wide stroke to the left side points us nicely and I'm then able to ever so subtly shift over onto the left hand side thus leaning the canoe in a stable yet visually precarious position. My haptic senses have acutely learned to perform this movement with balance, precision and power. A chiffchaff's signatory call pierces away in the woodland to the east as my green canoe weaves through the moored leisure craft. The morning coffee drinkers chatter and sip outside the café and from here at the southern tip of the lake the sunshine creeps and occasionally dashes through the clouds, fells and trees. How many others are starting their day in similar ways? Who's course am I following today? Who else would do this if I were not?

The synchronic gulp and gargle of water pushing and pooling around the wooden blade accompanies our navigated cutting path into unobstructed water. The water here becomes darker, murkier and visually more viscous as the paddle now no longer reaches or scratches the stony bed of the lake. We drive and pull deeper through this connection. The boat now feels a slightly different type of buoyancy at this depth as it skims through clumps of ribbon like green weed as the mouth of the bay opens up revealing the huge expanse of water ahead. Away from the shelter of the hills and woodland a warm summer breeze bends across my left 
cheek, elbow and hand as the canoe gently runs its path. The gentle westerly raises never ending and never starting regiments of small waves that persuade and coax the boat slightly to the right following every deep paddle stroke. The elemental nudge may be just two or three degrees off centre however the maintenance of course requires some minimal correction with each careful stroke. One assumption often made by non-paddlers is that solo paddling would require the alternation of stroke on both sides of the vessel. Such a method would render the efficiency and economics of movement for a whole trip (which could have been 16 hours for Voyageurs) as simply unsustainable. With the lean of the boat and rhythmic stroke pattern, a sensible power output coupled with precise correction can be sustained over huge distances.

Waskul and Waskul (2009) in their own paddling through the wilderness of Minnesota, eloquently take us on their journey through the waterways but also over the land as they portage through forest trails and make camp. Their leisure time away is peaceful and enjoyable it would appear yet also occasionally tiresome and hard slow work. Such 'work' or 'travail' of movement is a somatic type of work whereby the technics of mobility act as an 'extension of the senses' where 'to canoe is not only to move, but be moved' (36). Learning to enjoy the water, paddle the water and navigate therefore requires some form of sensuous epistemology and an aesthetic that is deeply haptic. Their time on water obscures and distorts their sense of speed and time, canoe travel brings one's pace down and Waskul and Waskul (2009) are rudely assaulted and jolted back into another dimension of speed and time upon their car journey back home.

The big deep gulping strokes and slop and slosh of shifting water now recede as a quiet, slow and isolating feeling arises within the slow carve through water. This environment generously opens up to us and its offering is welcomed. The occasional violating rumble of cars drift 
across the water as and when the nearby A592 runs close to the waters edge. Swish, flick, set and drawback. As the cars carry families along the seven or so miles to the popular Lakeland destination of Bowness-on-Windermere, my mind slowly wanders and expands amidst the cadenced swish, flick, set and drawback of me extended through wooden paddle. A rhythmic and almost meditative control motions us along this path of possible impossibility (Lingis, 1996).

This long thin paddle seems to extend with every stroke as it facilitates propulsion with an ever so slight kick and reverberation as it faintly bends under the imposed pressure. With this wooden extension of my body a 'functional unit' (Lingis, 1996) is formed and manipulated to perform one of the 'diagrams of movement from others' (15). The paddle dictates to a large extent what is done with it (much like the white cane of a visually impaired pedestrian) but in this connection there operates a space whereby the very humanness of being extends into and through the implement. There is a knack to this movement; such a knack largely evades language. The buoyancy, the bobbing and gentle pull and slide through the water blurs together as we slice into small coves or under overhanging trees or around protruding roots or boulders. A quick glance behind reveals a white bubbly meandering trail of the remnants of movement as the disturbed water gently resettles into its comfortable breeze induced ripple. My impression on the environment is temporary. The occasional caress of cool water on my left hand soothes and further connects me into this place. Droplets of water trickle down the paddle shaft or pop on the surface. Their drop and pop is audible because the boat is now silently slipping and arching under the precise control of my stroke. Through this narrowing aperture, the nymphs, small fry, swooping swallows, crows and fabric of nature become visible with sharper haptic focus. Our pace alters the visible. With a gradual twist of the paddle the boat's stern rotates and we rest perfectly motionless and silently to watch a grey 
wagtail perform its customary dipping action atop a humped grey slab of limestone that leans into the clear margins. The breeze tries to buffet the stern of the boat into the shore but a silent and instinctive reach and plunge of the paddle mitigates its effect and prevents us from pointing abruptly at our feathered companion.

The approach into the shore has been silent and smooth due to the particular stroke adopted. I use what has traditionally been called the 'Indian stroke' or 'Native stroke' to slide into the waters edge. It is sometimes also referred to as the 'silent stroke' for this reason and for hunters; it would have enabled the effective stalking of moose or other animals. During most of the journey this morning I've used a conventional ' $J$ stroke' that just like the letter, involves drawing the blade backward along the side of the boat before flicking it around and slightly away from the boat to subtlety correct the line of travel. Then, remove the blade from the water, lean forward a little and repeat over and over. This repetitive mundane movement avoids all the mess of frantically switching sides, splashing and needlessly bringing water into the boat.

The silent approach is similar to the ' $\mathrm{J}$ ' but the paddle never leaves the water, instead the flicking (the tail of the letter ' $\mathrm{J}$ ') involves not just a twist of my wrist but a complete rotation of the handle in the palm of my right hand and shaft in my left. The rotating slice of a perfectly carved thin blade arches forward through the water and returns at the top of the stroke thus leaving a narrow cut and sharp trail through the surface. The movement quietly fizzes and zips as tiny bubbles quickly rise and pop thus illustrating the shape of the movement. The elliptical circle of this stroke is mesmerising as we slip effortlessly through the dappled shade. My rotation continues to fizz and then slow as the blade is gently flicked with course corrected before it is drawn back with a long, deep yet delicate kick of 
propulsion. This drawing back silently disrupts the surface and momentarily leaves an absence of shifted water. The haptic control and contact continues throughout the whole stroke but this fleeting absence of water proves fascinating. With paddle about to rotate for more fizzing, the mass of Lake Windermere effortlessly reclaims control as the void left by me and my paddle is again gently filled with more water. Our song is of the silent kind.

The adjective 'carve' is to be emphasised. My paddle was carefully, slowly and expertly crafted through the meticulous carving of wood with hand tools. What is for Tim Rowe a very mundane activity is also a proud and pleasurable time spent turning, working and continually refining wood with a certain knack. I vaguely recall somebody saying how every plank of wood contains a paddle; Tim's craft involves carving away 'everything that is not paddle', with it in my hands, I now carve through water making as little disturbance as possible. Similar to Tim with his woodcraft, I see leisure as about taking away all that is not necessary.

The simple act of paddling this way with precision and force $i$ an aesthetic experience. A force is created by me in the water but when this exertion ends and I rotate and then the paddle zips, the impact still exists somewhere in the water around and behind the canoe. This experience has no such aesthetic property, its very hapticity just is aesthetic, it is an experience or knack that is grasped. The force of my haptic extension through the paddle is inevitably temporary yet the overall effect of this movement continues to be felt as a recoiling feeling of propulsion. I am grasped in this environment. This recoiling propulsion, this rhythmic pulling and relaxing is one of firm connection, it is almost spiritual. The 'rhythm and reverberation' (Lingis, 1996, 21) is deeply enjoyable as the effects of my pressure on the water are only meaningful because of the reciprocal pressures exerted by the water. This simply is what Fisher (1997) describes as the proximal and distal nature of perception through 
the haptic. 'In this sense haptic perception can elucidate the energies and volitions involved in sensing space: its temperature, presences, pressure and resonances... it is the affective touch, a plane of feeling distinct from actual physical contact' (4). Put this way, the haptic is understood somewhat very similarly to sound. It can be incredibly distal yet proximal and the sounds (or indeed lack of) that are made during this leisure travel become enmeshed within the broader soundscape, haptic space and cultural formation. I, complete with paddle and canoe contribute to the ecology and aesthetics of the water in rhythmic push and pull.

Canoeing does have a spiritual significance argues Peace (2009). From the design of the boat and paddle, the portaging, the people with whom one paddles (or indeed does not; isolation and solitude also prove important) and the central repetitiveness of paddling, great significance is afforded to the historical, immediate and also transcendent qualities of travelling by canoe. In an interesting sonic connection, Podruchny (2006) illustrates how voyageurs would perform songs much like the sea shanty's sung by workers as they labor the seas. The repetitive and rhythmic paddling of the canoe would have been accompanied with everyday work songs that 'allowed voyageurs to turn their work into lively and repetitive songs, which helped them maintain a pace, pass the time' (Podruchny, 2006, 93). Today here on the water I don't sing vocally, however my paddling, much like the skating of the aural architects in Maier's (2016) research, is a significant sonic accompaniment to the terrain and experience of leisure. This particular song is just from a different genre of music and my movement is one of slow pleasurable leisure.

\section{Concluding thoughts}

Our connection or contestation with environments during leisure can be charted by understanding the concept of haptic aesthetics. Paddling has been described to show how engagement with leisure equipment can be understood as a 'functional unit' to follow 
Alphonso Lingis (1996). This paper has described the intimate, proximal and distal workings of the haptic senses (Fisher, 1997) by the humble means of me with water, a canoe and paddle creating such a haptic unit of movement. In this way, like Waskul and Waskul (2009), it has been shown how one is humbly moved in, moved with and moved by, water. The touching, and being touched by water, technologies and environment (Allen-Collinson and Hockey, 2011) can evoke pleasurable feelings of peace, slowness and connection. This paper contributes a philosophical discussion to the growing corpus of research that has approached the haptic senses to understand the embodiment of leisure, place and geographies (Crouch, 2010). A critical argument has been posed concerning the social, cultural and economic proliferation of equipment and technologies that are designed to instigate and develop certain haptic aesthetics or 'reverberations' (Lingis, 1996) during leisure and also broader everyday technological life. At a time when we are becoming increasing encroached upon by certain technologies we seem to be encroaching upon nature and the environment with increasingly damaging effects. How we feel and feel with, hear and sound out to the environment is all part of an evolving ecological aesthetic that should not be ignored in analyses of leisure activity. One hopes that the focus on equipment and technologies helps further provoke some thoughts about our haptic aesthetics of leisure and also the soundscapes that we in part compose.

Equally, this paper has provided reasons for why a refocus on the aesthetic as being a sensuous and haptic concept within the embodiment debate brings us more into contact with our surroundings and in my implicit working with and blurring of the three layers of sound (Traux, 1978) in this paper, it has been shown how the haptic is an ensemble of touch, vision and audition (Fisher, 1997). In offering a description of the silence of my song, it has been shown how our sensory entwinement (Merleau-Ponty, 1969; Hockey and Allen-Collinson, 
2007; Allen-Collinson, 2009) with environmental soundscapes is epistemological, aesthetic and also in part ethical where and when the fluent, peaceful, connected qualities of paddling are considered. It is in the mundane, motion and repetitiveness of exercise (Caudwell, 2015; Hockey, 2006) the intense embodiment and strangely pleasurable discomforts of leisure (Allen-Collinson and Leledaki, 2015), that it is in no doubt clear how our leisure pursuits are in part sensuous and therefore aesthetic. As arbiters of the aesthetic, leisure consumers are actively involved in their shaping and entwining of contemporary outdoor leisure and its associated aesthetic fabric and it is hoped that this paper fuels a little critical thought about the trajectory and paths of aesthetics and some embodiment trappings.

\section{Acknowledgments}

The author would like to thank Tim Rowe at Edenwood Paddles for his beautiful craft, without which this paper would not have been inspired or written. Additional thanks have to go to the anonymous reviewers whose thoughtful comments have enabled me to further refine and develop my ideas.

\section{Funding}

The author has received no funds for the completion of this work.

\section{Disclosure statement}

No potential conflict of interest was reported by the author.

\section{Biographical note}

Chris Hughes is a lecturer at Edge Hill University. He received a PhD from Leeds Beckett University for the thesis 'The Senses, the self and the physically active body: A sensual 
ethnography of bouldering' written under the supervision of Professor Andrew C. Sparkes. In drawing inspiration from anthropological, philosophical and sociological conceptualisations of the body, his research seeks to explore the senses and everyday aesthetics in physical culture.

\section{References}

Allen-Collinson, J. (2009). Sporting embodiment: sports studies and the (continuing) promise of phenomenology. Qualitative Research in Sport and Exercise, 1 (3), pp. 279296.

Allen-Collinson, J. \& Hockey, J. (2011). Feeling the way: Notes towards a haptic phenomenology of distance running and scuba diving. International Review for the Sociology of Sport. (46) 3, 330-345.

Allen-Collinson, J. \& Leledaki, A. (2015). Sensing the outdoors: A visual and haptic phenomenology of outdoor exercise embodiment. Leisure Studies, (34) 4, 457-470.

Apple. (2017). Apple reports second quarter results. Apple, May $2^{\text {nd }} 2017$. Accessed $21^{\text {st }}$ May 2017. https://www.apple.com/uk/newsroom/2017/05/apple-reports-second-quarter-results/

Blesser, B \& Salter, L. (2007). Spaces Speak, Are You Listening? Experiencing Aural Architecture. Massachusetts: MIT Press.

Brown, M. (2017). The offshore sailor: enskilment and identity. Leisure Studies, (36) 5, 684695.

Butler, D. (2016). Regaining a "feel for the game" through interspecies sport. Sociology of Sport Journal. Advance Online Publication. DOI: 10.1123/ssj.2016-0091

Caudwell, J. (2015). 'Feeling blue': The ordinary pleasures of mundane motion. Qualitative Research in Sport, Exercise and Health. (7) 3, 309-320.

Collins, M. (2011). The politics of the environment, and noisy sports: two totally different outcomes in the Lake District National Park for powerboating and off-road motoring. Leisure Studies. (30) 4, 423-452.

Crouch, D. (2010). Places around us: Embodied lay geographies in leisure and tourism. Leisure Studies, (19) 2, 63-76.

Deleuze, G \& Guattari, F. (1988). A Thousand Plateaus: Capitalism and Schizophrenia. London: Athlone.

Fisher, J. (1997). Relational sense: towards a haptic aesthetics. Parachute. (87) 1, 4-11. 
Hockey, J. (2006). Sensing the run: The senses and distance running. The Senses and Society. (1) $2,183-202$.

Hockey, J. \& Allen-Collinson, J. (2007). Grasping the phenomenology of sporting bodies. International review for the sociology of sport. (42) 2, 115-131.

Humberstone, B. (2011). Embodiment and social and environmental action in nature-based sport: Spiritual spaces. Leisure Studies. (30) 4, 495-512.

Ingold, T. (2004). Culture on the ground: The world perceived through the feet. Journal of Material Culture. (9) 3, 315-340.

Jackman, P. C., Fitzpatrick, G., Lane, A \& Swann, C. (2017). Exploring bodily sensations experienced during flow states in professional national hunt jockeys: A connecting analysis. Qualitative Research in Sport, Exercise and Health. Advance Online Publication http://dx.doi.org/10.1080/2159676X.2017.1380693

Kapralos, B, Collins, K \& Rribe-Quevedo, A. (2017). The senses and virtual environments. The Senses and Society. (12) 1, 69-75.

Kerry, D. S., Armour, K. M. (2000). Sports sciences and the promise of phenomenology: Philosophy, method, and insight. Quest, 52 (1), pp. 1-17.

LaBelle, B. (2010). Acoustic Territories: Sound Culture and Everyday Life. New York: Continuum.

Leder, D. (1990). The Absent Body. Chicago: University of Chicago Press.

Lingis, A. (1996). Sensation: Intelligibility in Sensibility. New Jersey: Humanities Press International Inc.

Maier, C. (2016). The Sound of skateboarding: Aspects of a transcultural anthropology of sound. The Senses and Society. (11) 1, 24-35.

Merleau-Ponty, M. (1962). Phenomenology of Perception. Translated by C. Smith. London: Routledge \& Kegan Paul.

Merleau-Ponty, M. (1969). The Visible and the Invisible. Translated by A. Lingis. Evanston, IL: North-western University Press.

Merchant, S. (2011). The body and the senses: Visual methods, videography and the submarine sensorium. Body and Society. (17) 53, 53-72.

Nike. (2017). Nike, inc. 'Reports Fiscal 2017 Third Quarter Results'. Nike, March $21^{\text {st }} 2017$. Accessed $17^{\text {th }}$ April 2017. http://news.nike.com/news/nike-inc-reports-fiscal-2017-thirdquarter-results

Palmer, C. (2016). Boots-and-me: An ethno-sensual account of love, dedication and smelly old boots. Journal of Qualitative Research in Sports Studies. (10) 1, 269-29. 
Paterson, M. (2007). The Senses of Touch: Haptics, Affects and Technologies. Oxford: Berg.

Peace, T. (2009). Journeying by canoe: Reflections on the canoe and spirituality. Leisure/ Loisir. (33) 1, 217-239.

Podruchny, C. (2006). Making the voyageur world: Travellers and Traders in the North American Fur Trade. Toronto: University of Toronto Press.

Seremetakis, N., ed. (1994). The Senses Still: Perception and Memory as Material Culture in Modernity. Oxford: Westview.

Sparkes, A. C. (2009). Ethnography and the senses: Challenges and possibilities. Qualitative Research in Sport and Exercise. (1) 1, 21-35.

Sparkes, A. C., ed. (2017). Seeking the Senses in Physical Culture. Abingdon: Routledge.

Sport England. (2013). Economic Value of Sport in England. Sport England, July 2013. Accessed $2^{\text {nd }}$ May 2017. https://www.sportengland.org/media/3465/economic-value-ofsport.pdf

Truax, B., ed. (1978). Handbook for Acoustic Ecology. Vancouver: A. R. C Publications.

Waskul, D. \& Waskul, M. (2009). Paddle and Portage: The Travail of BWCA Canoe Travel. In The Cultures of Alternative Mobility, edited by Phillip Vannini, 21-37. Aldershot: Ashgate.

Young, I. (1990). Throwing Like a Girl and Other Essays in Philosophy and Social Theory. Bloomington: Indiana University Press. 